\title{
Effect of Microsize Particulates on Tribological Characteristics of Vinylester Composites under Dry and Lubricated Conditions
}

\author{
S.R.Chauhan', Bharti Gaur ${ }^{2}$ and Kali Dass ${ }^{1 *}$
}

${ }^{1}$ Department of Mechanical Engineering, National Institute of Technology, Hamirpur, India

${ }^{2}$ Department of Chemistry, National Institute of Technology, Hamirpur, India

\begin{abstract}
In this paper the friction wear characteristics of vinylester and vinylester composites have been investigated under dry and water lubricated sliding conditions, under different applied normal load and sliding speed. The experiments have been carried on a pin on disc arrangement at normal temperature conditions. The results showed that with increase in the applied normal load and sliding speed the coefficient of friction and specific wear rate decreases under both dry and water lubricated sliding conditions. It is also found that a thin film formed on the counterface seems to be effective in improving the tribological characteristics. The worm surface examined by SEM showed that more of the fiber exposure and fiber breakage for vinylester composite resulting higher wear rate.
\end{abstract}

Keywords: Coefficient of friction; Specific wear rate; Glass vinylester composites

\section{Introduction}

In recent years, Polymers are extensively used in active engineering components such as gears and cams where their self lubricating properties are exploited to avoid the need for oil or grease lubrication with its attendant problems of sealing and possible contamination. Many polymers based composites are widely used for sliding couples against metals, polymers and other materials. However, where the contact is there, there is the problem of friction and wear. The importance of tribological properties convinced many researchers to study the friction and wear behavior and to improve the wear resistance of polymeric composites. For fiber reinforced polymer matrix composites the process of material removal in dry sliding condition is dominated by four wear mechanisms, viz., matrix wear, fiber sliding wear, fiber fracture and interfacial debonding [1-3]. A number of material-processing strategies have been used to improve the wear performance of polymers. Use of inorganic fillers dispersed in polymeric composites is increasing. Fillers not only reduce the cost of the composites, but also meet performance requirements, which could not have been achieved by using reinforcement and resin ingredients alone. In order to obtain perfect friction and wear properties many researchers modified polymers using different fillers [4-8].

Compared with the glass and carbon-fibre reinforced counterparts, aramid-fibre filled polymer composites have an intermediate friction and an intermediate wear factor while the wear of their metallic counter faces is low. Adding aramid fibre to phenolic resin resulted in a $30-40$ fold increase in the wear resistance while the friction remained high even at high sliding speeds and pressures. This characteristic makes the material a potential candidate for brake shoes [9].

It has been found that under most conditions the coefficient of friction and wear rate were less when fibers are normal to the sliding surface. In most of the tribological applications, the materials are subjected to stringent conditions of loads, speeds, temperatures and hazardous environment [10]. There have been numerous reports on the tribological behavior of Fiber-Reinforced Polymer Composites (FRPCs) because of the possibility of using polymer composites for wear-sensitive applications [11-15].

Glass fiber-reinforced polymer composites are well established although carbon fiber reinforced composites start to enter this field of application. Currently, due to considerations of cost and ease of processability, low viscosity vinylester resins that may be cured at room temperature are being used in preference to epoxy resins $[16,17]$. Suresh et al. [18], investigated the wear behavior of glass fiber, carbon fiber and carbon bead-reinforced polytetrafluoroethylene (PTFE). The glass-reinforced PTFE showed a very low wear rate with a steel counter face and finally concluded that the fiber preferentially supports the applied load and a fiber rich layer is produced during rubbing action on the mating surface. Chauhan et al. [19], studied the friction and dry sliding wear behavior of carbon and glass fabric reinforced vinylester composites. They concluded that the coefficient of friction and wear rate increased with increase in load/sliding velocity and depends on type of fabric reinforcement and temperature at the interphase. The excellent tribological characteristics were obtained with carbon fiber in vinylester. Dwivedi et al. [20], studied the mechanical and wear characterization of glass fiber reinforced vinyl ester composites with different co-monomers. They concluded that glass fiber reinforced vinyl ester with styrene as co-monomer has the best mechanical and wear properties.

Vinyl ester resins were first introduced commercially in early 1960's [21]. Today they are one of the most important thermosetting materials. Vinyl ester resins have been widely recognized as materials with excellent resistance to a wide variety of commonly encountered chemical environments. Vinyl ester resins are used to fabricate a variety of reinforced structures [22-25] including pipes, tanks, scrubber and ducts. They are the prime candidates for use in composite for transportation and/or infrastructure. Vinylester is a hybrid form of polyester resin which has been toughened with epoxy molecules within the main molecular structure. Vinylester resins offer better resistance

${ }^{*}$ Corresponding author: Kali Dass, Research Scholar, Department of Mechanical Engineering, National Institute of Technology, Hamirpur, India, E-mail: thakurkalidass999@gmail.com

Received October 26, 2012; Accepted November 19, 2012; Published November 27,2012

Citation: Chauhan SR, Gaur B, Dass K (2013) Effect of Microsize Particulates on Tribological Characteristics of Vinylester Composites under Dry and Lubricated Conditions. J Material Sci Eng 2:117. doi:10.4172/2169-0022.1000117

Copyright: (c) 2013 Chauhan SR, et al. This is an open-access article distributed under the terms of the Creative Commons Attribution License, which permits unrestricted use, distribution, and reproduction in any medium, provided the original author and source are credited. 
to moisture absorption than polyester resins. It is also known that vinylester resins bond very well to fiber glass [26]. Some researchers in their investigation on the tribological behavior of high density polyethylene, polyamide and their composites reported that the wear resistance and coefficient of friction is affected greatly by normal load, sliding speed and temperature [27-29]. Many studies reported that the wear resistance with polymer sliding against steel improved when the polymers are reinforced with glass or aramid fibres. However, the behaviour is affected by factors, such as the type, amount, size, shape and orientation of the fibres, the matrix composition and the test conditions, such as load, speed and temperature [30-32]. Many researchers [33-35] showed that the introduction of water into a polymer and metal sliding combination generally reported that the coefficent of friction under water lubricated condition is lower than that of the dry sliding condition. Therefore in this paper the effect of microsize particulates on tribological characteristics of vinylester composites under dry and lubricated conditions for the accurate knowledge of the influence of sliding speed and applied normal load on the friction and wear behaviour.

\section{Experimental Details}

\section{Experimental materials and manufacturing method}

Vinylester resins are addition products of various epoxide resins and unsaturated monocarboxylic acids, most commonly methacrylic acid [19]. The final steps involved in preparation of vinylester resin from the synthesis of ortho-cresol formaldehyde novolac are shown in figure 1 .

Glass fibers had super sizing for ease of handling, fast wet out, and compatibility with a number of resins including vinylester resin. The type of resin used in this work is vinylester resin (density 1.23 $\mathrm{g} / \mathrm{cm}^{3}$ and Modulus 2.3-4 MPa) and reinforcing phase E-glass fibers (modulus $72.4 \mathrm{GPa}$, density $2.54 \mathrm{~g} / \mathrm{cm}^{3}$ ) were supplied by Northern Polymer Pvt. Ltd. New Delhi. Methyl ethyl ketone peroxide (MEKP$1 \%)$, Cobalt Naphthenate (1.5\%) were used as catalyst and accelerator respectively. Four different types of specimens were prepared for this study. Conventional wet hand layup technique was used for making of the glass vinylester composite laminates. The Cobalt Naphthenate $1.5 \%$ was mixed thoroughly in vinylester resin and then $1 \%$ MEKP was mixed in the resins prior to reinforcement. The fiber loading (weight fraction of glass fiber in the composite) was kept $50 \mathrm{wt} \%$ for all the samples. The stacking procedure consists of placing the fabric one above the other with the resin mix well spread between the fabrics on a mould release sheet. A porous Teflon film was again used to complete the stack.

To ensure uniform thickness of the sample, a $3 \mathrm{~mm}$ spacer was used. The mould plates were coated with release agent in order to aid the ease of separation on curing. The similar procedure was repeated in all cases unless thickness of $3 \mathrm{~mm}$ was obtained. A metal roller was used so that uniform thickness and compactness could be obtained. The whole assembly was placed in the compression molding machine at a pressure of $60 \mathrm{Kgf} / \mathrm{cm}^{2}$ and allowed to cure at room temperature for $24 \mathrm{hrs}$. The laminate sheets of sizes $300 \times 300 \times 3 \mathrm{~mm}^{3}$ were prepared. Specimens of suitable dimensions were cut using a diamond cutter for wear testing. The alumina fillers $(40-80 \mu \mathrm{m})$ were mixed thoroughly in the vinylester resin mechanically before the glass fiber mats were reinforced in the matrix body.

\section{Friction and wear measurements}

The friction and sliding wear performance evaluation of vinylester and its composites $\mathrm{C}_{1}, \mathrm{C}_{2}, \mathrm{C}_{3}$ and $\mathrm{C}_{4}$ under dry and water lubricated sliding conditions, wear tests were carried out on a pin-on-disc type friction and wear monitoring test rig (DUCOM) as per ASTM G 99. The counter body is a disc made of hardened ground steel (EN-32, hardness $72 \mathrm{HRC}$, surface roughness $0.7 \mu \mathrm{Ra}$ ). The specimen is held stationary and the disc is rotated while a normal force is applied through a lever mechanism. During the test, friction force was measured by transducer mounted on the loading arm. The friction force readings are taken as the average of 100 readings every 40 seconds for the required period. For this purpose a microprocessor controlled data acquisition system is used. A series of test were conducted with three sliding velocities of $1.6,2.8$, and $4 \mathrm{~m} / \mathrm{s}$ under three different normal loading of 10,30 and $50 \mathrm{~N}$. Weight loss method was used for finding the specific wear. During these experiments initial and final weight of the specimens were measured.

The material loss from the composite surface is measured using a precision electronic balance with accuracy $\pm 0.01 \mathrm{mg}$. The specific wear rate $\left(\mathrm{mm}^{2} / \mathrm{N}\right)$ is then expressed on 'volume loss' bases

$$
K_{s}=\frac{\Delta M}{\rho L F_{N}}
$$

Where $\mathrm{K}_{\mathrm{s}-\text { is }}$ the specific wear rate $\left(\mathrm{mm}^{2} / \mathrm{N}\right), \Delta \mathrm{M}$ - is the mass loss in the test duration (gm)

$\rho$ - Is the density of the composite $\left(\mathrm{gm} / \mathrm{cm}^{3}\right) \mathrm{FN}$ is the average normal load $(\mathrm{N})$.

\section{Scanning electron microscope}

A Scanning Electron Microscope (SEM) was used to analyze the worn surface of the composites. Worn surface samples were mounted on aluminum stub using conductive (silver) paint and were sputter coated with gold prior to SEM examination. The surfaces of the vinylester composites specimens were examined directly by scanning electron microscope JEOL JSM-6480LV. The composite samples were mounted on stubs with silver paste. To enhance the conductivity of the samples, a thin film of platinum was vacuum-evaporated onto them before the photomicrographs are taken.

\section{Results and Discussion}

In the present work, the dry and water lubricated sliding friction and wear behavior of pure vinylester composite sample $\mathrm{C}_{1}$, composite samples $\mathrm{C}_{2}$ (vinylester $+50 \mathrm{wt} \% \mathrm{GFR}$ ), $\mathrm{C}_{3}$ (vinylester $+50 \mathrm{wt} \% \mathrm{GFR}+10$ $\mathrm{wt} \%$ Alumina) and $\mathrm{C}_{4}$ (vinylester $+50 \mathrm{wt} \% \mathrm{GFR}+20 \mathrm{wt} \%$ Alumina) have been studied in terms of the coefficient of friction and specific wear rate.

The detailed compositions of the materials taken for the test conditions and parameters considered for experimentation scheme are presents in table 1 . Figures $2 \mathrm{a}-2 \mathrm{c}$ present the variation of coefficients of friction with applied normal load values $(10,30$ and $50 \mathrm{~N})$ at different sliding speeds of $(1.6,2.8$ and $4.0 \mathrm{~m} / \mathrm{s})$ under dry and water lubricated sliding conditions. The experimental results show that with increase in the applied normal load the coefficient of friction decreases for pure

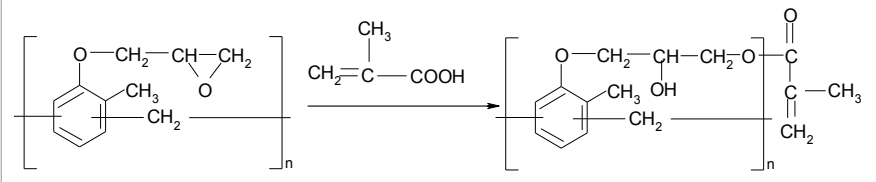

Figure 1: Preparation of vinylester resin based on O-cresol novolac resin 
Citation: Chauhan SR, Gaur B, Dass K (2013) Effect of Microsize Particulates on Tribological Characteristics of Vinylester Composites under Dry and Lubricated Conditions. J Material Sci Eng 2:117. doi:10.4172/2169-0022.1000117

Page 3 of 6

\begin{tabular}{|c|c|c|c|c|c|c|}
\hline Materials & Composite Specification & Density $\mathrm{gm} / \mathrm{cm}^{3}$ & Temperature $\left({ }^{\circ} \mathrm{C}\right)$ & Humidity (\%) & Load $(\mathrm{N})$ & Sliding speed $(\mathrm{m} / \mathrm{s})$ \\
\hline $\mathrm{C}_{1}$ & Pure Vinylester & 1.23 & 29 & 65 & $\begin{array}{l}10 \\
30 \\
50\end{array}$ & $\begin{array}{l}1.6 \\
2.8 \\
4.0\end{array}$ \\
\hline $\mathrm{C}_{2}$ & Vinylester $+50 w t \%$ glassfiber & 2.29 & 29 & 65 & $\begin{array}{l}10 \\
30 \\
50\end{array}$ & $\begin{array}{l}1.6 \\
2.8 \\
4.0\end{array}$ \\
\hline $\mathrm{C}_{3}$ & $\begin{array}{c}\text { Vinylester }+50 \text { wt } \% \text { glassfiber+ } 10 w t \% \\
\text { Alumina }\end{array}$ & 2.30 & 29 & 65 & $\begin{array}{l}10 \\
30 \\
50\end{array}$ & $\begin{array}{l}1.6 \\
2.8 \\
4.0\end{array}$ \\
\hline $\mathrm{C}_{4}$ & $\begin{array}{c}\text { Vinylester }+50 w t \% \text { glassfiber }+20 w t \% \\
\text { Alumina }\end{array}$ & 2.15 & 29 & 65 & $\begin{array}{l}10 \\
30 \\
50\end{array}$ & $\begin{array}{l}1.6 \\
2.8 \\
4.0\end{array}$ \\
\hline
\end{tabular}

Table 1: Materials and Test Conditions.

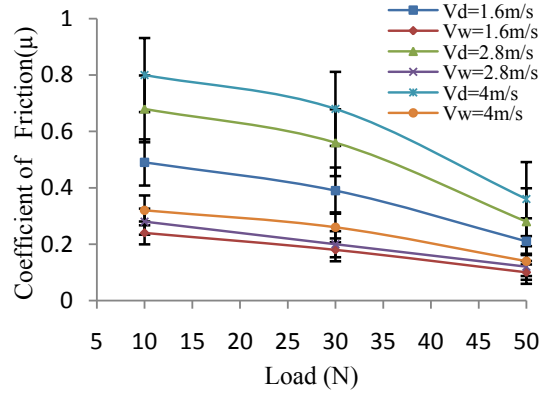

(a)

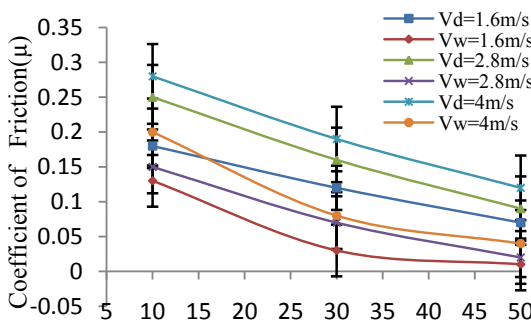

$\operatorname{Load}(\mathrm{N})$

(c)

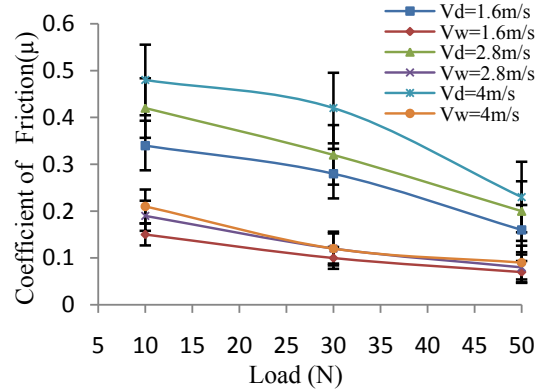

(b)

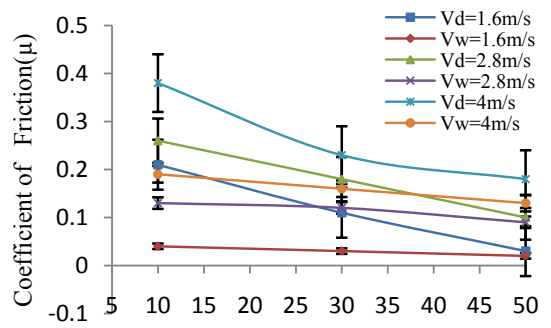

$\operatorname{load}(\mathrm{N})$

(d)

Figure 2: Variation of coefficient of friction with normal load under dry and water lubricated sliding conditions (a) $C_{1}\left(\right.$ b) $C_{2}$ (c) $C_{3}$ and (d) $C_{4}$.

vinylester and its composites at sliding speed of $(1.6,2.8$ and $4.0 \mathrm{~m} / \mathrm{s})$ and applied normal load of $(10,30$ and $50 \mathrm{~N})$ under both dry and water lubricated condition.

In all test condition the coefficient of friction was maximum in case of pure vinylester $\left(\mathrm{C}_{1}\right)$ under dry condition and minimum in case of ceramic filled vinylester composites $\left(\mathrm{C}_{3}\right.$ and $\left.\mathrm{C}_{4}\right)$. However in case of water lubricated sliding conditions the coefficient of friction is less as compare to the dry sliding conditions. Under dry sliding conditions increasing applied normal load and sliding speed increases the temperature at the interface. This increase in temperature causes thermal penetration to occur, which results in weakness in bond at the fiber-matrix interface. Consequently fibers become the loose in the matrix and shear easily due to axial thrust. As a result coefficient of friction decreases $[3,18,28,36]$. It was also found that the transfer film also plays a very important role in affecting the friction and wear behavior of fiber reinforced vinylester composites. However under water lubricated conditions the presence of water at the interface as lubricant diminishes the effect of temperature and friction mechanism at the interface is predominated by occurrence of hydrodynamic film thickness and due this reason friction reduces under water lubricated conditions $[35,37,38]$.

Figures $3 \mathrm{a}-3 \mathrm{~d}$ present the variation of specific wear rate for vinylester and its composites $\left(\mathrm{C}_{1}, \mathrm{C}_{2}, \mathrm{C}_{3}\right.$ and $\left.\mathrm{C}_{4}\right)$ with applied normal load $(10,30$ and $50 \mathrm{~N})$, test speeds $(1.6,2.8$ and $4.0 \mathrm{~m} / \mathrm{s})$ under both dry and water lubricated sliding conditions. Figure 3 a shows that the specific wear rate for pure vinylester is influenced by the change in applied normal load both under dry and water lubricated sliding conditions. The specific wear rate increases with increase in applied normal load under dry sliding conditions. The higher the sliding speed the higher is the specific wear rate in dry sliding conditions. The specific wear rate values at water lubricated condition are close to each other at sliding speeds of 1.6, 2.8 and $4 \mathrm{~m} / \mathrm{s}$. However the specific wear rate increases with increase in applied load at sliding speeds of $1.6 \mathrm{~m} / \mathrm{s}$ and decreases with increase in applied load at sliding speeds of 2.8 and $4 \mathrm{~m} / \mathrm{s}$ under water lubricated sliding conditions.

From the observations of Figures $3 \mathrm{~b}-3 \mathrm{~d}$ it is seen that the specific 
wear rate decreases with increase in applied normal load both under dry and water lubricated sliding conditions. Under water lubricated sliding conditions it is explained by removal of the film layer underwater lubricated condition as well as cooling effect at the interface due to the presence of water. Though the water inhibit the formation of transfer films of fiber glass/polymer debris on the counter-face and the specific wear rates are close to those obtained in dry sliding conditions [37]. The highest wear rate is for pure vinylester under dry sliding conditions at $1.6 \mathrm{~m} / \mathrm{s}$ sliding speed and load of $50 \mathrm{~N}$. The lowest wear rate for vinylester composite $\mathrm{C}_{4}$ (vinylester+GFR $50 \mathrm{wt} \%+20 \mathrm{wt} \%$ alumina) composite under dry conditions at $4.0 \mathrm{~m} / \mathrm{s}$ sliding speed and applied normal load $50 \mathrm{~N}$.

\section{Scanning electron microscope based on friction and wear data}

During sliding, both adhesive and abrasive wear mechanisms are operative, resulting in powdery wear debris. The frictional heat generated at the interface caused thermal softening of the matrix and some of the powdery wear debris got embedded into the matrix and formed a protective layer. The optical microscopy examination of worn surfaces of vinylester composites $\left(\mathrm{C}_{2}, \mathrm{C}_{3}\right.$ and $\left.\mathrm{C}_{4}\right)$ against steel discs both dry and water lubricated sliding conditions under applied load of $50 \mathrm{~N}$ and $4 \mathrm{~m} / \mathrm{s}$ sliding speed are given in Figures $4 \mathrm{a}-4 \mathrm{f}$.

The disc worn surfaces for vinylester composite $\left(\mathrm{C}_{2}\right)$ show that more of the fiber exposure and fiber breakage indicating higher wear rate. However under water lubricated conditions from the Figure $4 \mathrm{~b}$ the wear debris formations are not seen on the worn surface which indicates that water washes away the wear debris and fibres are exposed to the steel surface which indicated less wear. From figure $4 \mathrm{c}$ for composite samples $\left(\mathrm{C}_{3}\right)$ the observations show that under dry sliding conditions the matrix is uniformly spreaded over major portion of the specimen and only small amount of the fibers are exposed but in figure $4 \mathrm{~d}$ shows the large amount of fiber exposure and matrix and hence higher wear rate.

Figures $4 \mathrm{e}-4 \mathrm{f}$ shows the spread of matrix, long fibres exposure as well as debris formation also it is observed that fiber exposure is more under water lubricated sliding conditions. These observations show agreement with the experimental results that wear rate is lesser than the glass vinylester composite $\left(\mathrm{C}_{2}\right)$. The difference in wear rate between the composite specimens under water lubricated and dry sliding conditions can be attributed to the film removal under water lubricated sliding conditions. Water prevent the formation of the transfer films of the fibre glass/vinylester matrix and ceramic filler particulates on the interface of specimen and counterface of steel by removing the debris and specific wear rates are close to those obtained in dry sliding condition.

\section{Conclusions}

The main aim of this research work is to investigate the influence of alumina ceramic particulate on friction and wear behavior of E-glass vinylester composites. An experimental study of friction and wear behavior of E-glass vinylester composites at different sliding speed, applied normal load can reveals the following:

- The coefficient of friction for vinylester and its composite decreases with increase in applied normal load and sliding speed under both dry and water lubricated sliding conditions.

- However under dry condition the specific wear rate increases with increase in the applied normal load for pure vinylester composites, but for vinylester composites $\left(\mathrm{C}_{2}, \mathrm{C}_{3}\right.$ and $\left.\mathrm{C}_{4}\right)$ the specific wear rate decreases with increase in applied normal load under both dry and water lubricated sliding conditions.

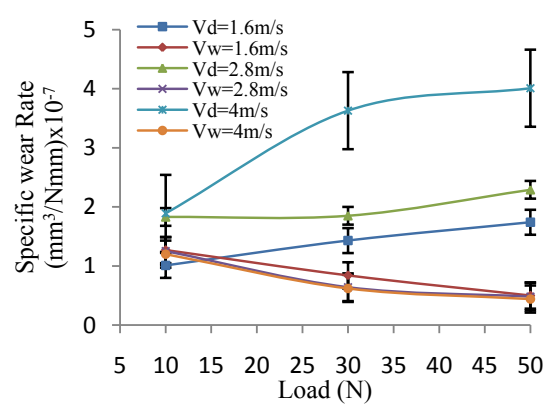

(a)

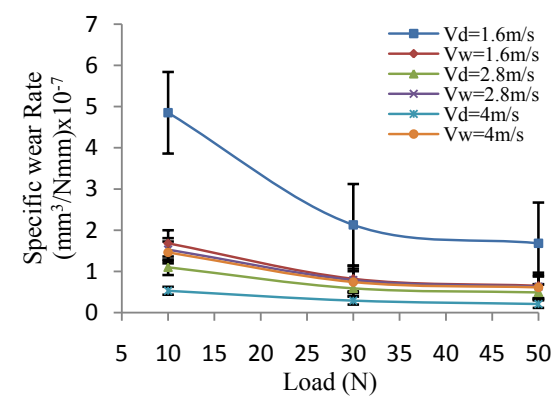

(c)

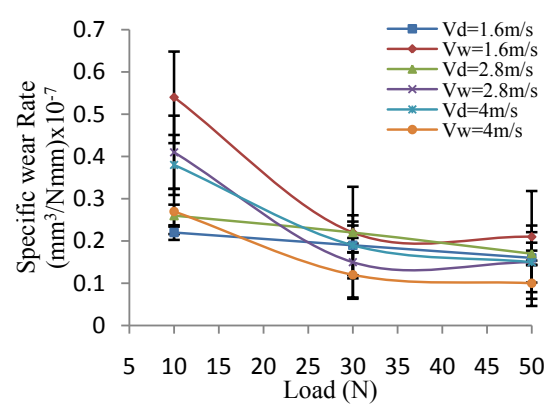

(b)

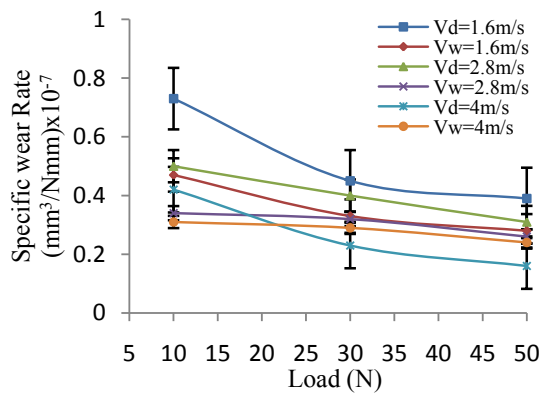

(d)

Figure 3: Variation of specific wear rate with normal load under dry and water lubricated sliding conditions (a) $C_{1}$ (b) $C_{2}$ (c) $C_{3}$ and (d) $C_{4}$. 
Citation: Chauhan SR, Gaur B, Dass K (2013) Effect of Microsize Particulates on Tribological Characteristics of Vinylester Composites under Dry and Lubricated Conditions. J Material Sci Eng 2:117. doi:10.4172/2169-0022.1000117

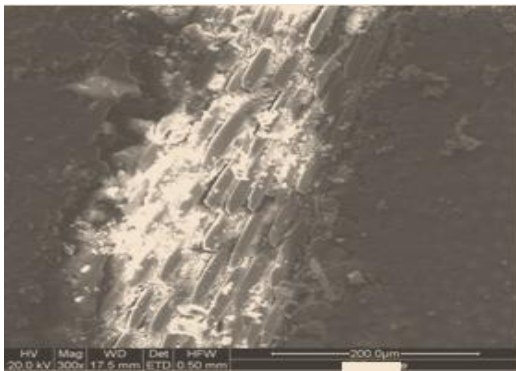

(a) SEM picture of sample $\mathrm{C}_{2}$ under dry sliding condition

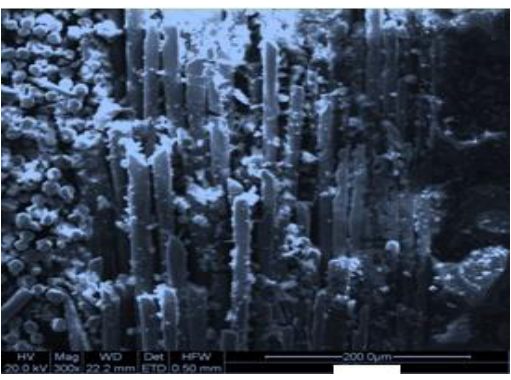

(c) SEM picture of sample $\mathrm{C}_{3}$ under dry sliding condition

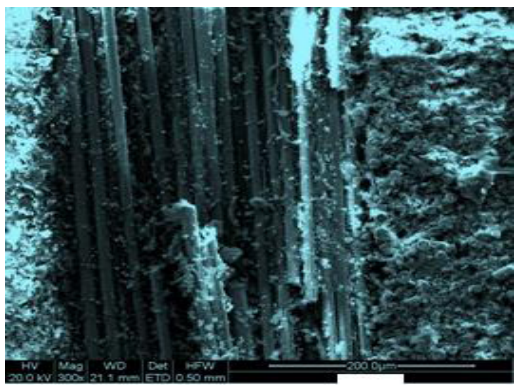

(e) SEM picture of sample $\mathrm{C}_{4}$ under dry sliding condition

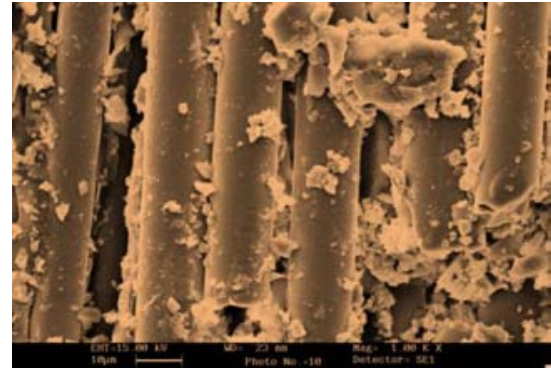

(b) SEM picture of sample $\mathrm{C}_{2}$ under water lubricated sliding conditions

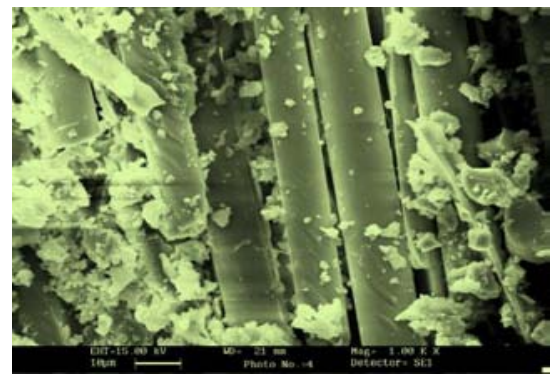

(d) SEM picture of sample $\mathrm{C}_{3}$ under water lubricated sliding conditions

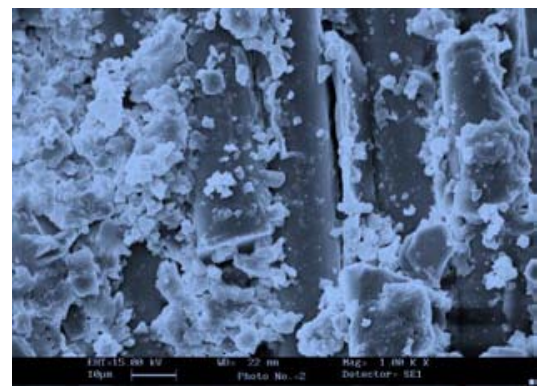

(f) SEM picture of sample $\mathrm{C}_{4}$ under water lubricated sliding conditions

Figure 4: (a-f) SEM picture vinylester composites $\left(C_{2}, C_{3}\right.$ and $\left.C_{4}\right)$ under dry and water lubricated sliding conditions.

- The friction coefficient under water lubricated sliding conditions for vinylester and its composites are lower than that of dry sliding conditions.

- Pure vinylester has higher specific wear rate due to small mechanical properties. Therefore reinforcement of glass fiber and alumina filler improves the wear characteristics both under dry and water lubricated conditions.

\section{References}

1. Kukureka SN, Hooke CJ, Rao M, Liao P, Chen YK (1999) The effect of fibre reinforcement on the friction and wear of polyamide 66 under dry rolling-sliding contact. Tribol Int 32: 107-116.

2. Unal H, Mimaroglu A, Kadıoglu U, Ekiz,H (2004) Sliding friction and wear behaviour of polytetrafluoroethylene and its composites under dry conditions. Mater Design 25: 239-245.

3. Friedrich K, Lu Z, Hager AM (1995) Recent advances in polymer composites tribology. Wear 190: 139- 44.

4. Suresha B, Chandramohan G, Prakash JN, Balusamy V, Sankaranarayanasamy K (2006) The Role of Fillers on Friction and Slide Wear Characteristics in GlassEpoxy Composite Systems. Journal of Minerals \& Materials Characterization \& Engineering 5: 87-101.
5. Briscoe BJ, Pogosian AK, and Tabor D (1974) The friction and wear of high density polythene: The action of lead oxide and copper oxide fillers. Wear 27 19-34.

6. Tanaka k (1986) Effect of various fillers on the friction and wear of PTFE- based Composites. In Friction and wear of polymer composites. 205: 137-174.

7. Bahadur S, Fu Q, and Gong D (1994) The effect of reinforcement and the symposium between CuS and carbon fiber on the wear of nylon. Wear 178 123-130.

8. Basavarajappa S, Chandramohan G (2005) Wear Studies on Metal Matrix Composites: a Taguchi Approach. J Mater Sci Technol 21: 845-850.

9. Kootsookos A, Mouritz AP (2004) Seawaterdurability of glass- and carbonpolymer composites. Compos Sci Technol 64: 1503-1511.

10. Hutchings IM (1992) Tribology: friction and wear of engineering materials Edward Arnold Publishers Ltd, London UK.

11. Tripaty, Furey BS, Michael J (1993) Tribological behaviour of unidirectional graphite- epoxy and carbon-PEEK composites. Wear 162: 385-396.

12. Suresha B, Chandramohan $G$, Sampathkumaran $P$, Seetharamu $S$, Vynatheya $S$ (2006) Friction and Wear Characteristics of Carbon-epoxy and Glass-epoxy Woven Roving Fiber Composites. J Reinf Plast Comp 25: 771-782.

13. Chang HW (1983) Wear characteristics of composites: Effect of fiber orientation Wear 85: 81-91. 
Citation: Chauhan SR, Gaur B, Dass K (2013) Effect of Microsize Particulates on Tribological Characteristics of Vinylester Composites under Dry and Lubricated Conditions. J Material Sci Eng 2:117. doi:10.4172/2169-0022.1000117

Page 6 of 6

14. Lyhmn C (1987) Tribological properties of unidirectional polyphenylene sulfidecarbon fiber laminate composites. Wear 117: 147-159.

15. Tanaka K (1977) Friction and wear of glass and carbon fiber filled thermoplastic Polymers. J Lub Tech 99: 408-415.

16. Karabhari, VM, Zhang S (2003) E-Glass/Vinylester Composites in Aqueous Environments-I: Experimental Results. Appl Compos Mater 10: 19-48.

17. Sinha SK, Biswas SK (1995) Effect of sliding speed on friction and wear of unidirectional aramid fibre-phenolic resin composit. J Mater Sci 30: 2430-2437.

18. Suresha B, Kumar KS, Seetharamu S, Kumaran SP (2010) Friction and dry sliding wear behavior of carbon and glass fabric reinforced vinyl ester composites. Tribol Int 43: 602-609.

19. Chauhan S, Kumar A, Patnaik A, Satapathy A, Singh I (2008) Mechanical and Wear Characterization of GF Reinforced Vinyl Ester Resin Matrix Composites With Different Co-Monomers J Reinf Plast Comp 28: 2675-2684.

20. Dwivedi DK, Kaith BS and Singha AS (2003) Preparation of Polystyrene Matrix Based Composites Using Flax -g-Copolymers as Reinforcing agents and evaluation of their Mechanical Behaviour. International Journal of Plastic Technology 7: 119-125

21. Yeh HY, and Yang SC (1997) Building of a Composite Transmission Tower. J Reinf Plast Comp 16: 414-424.

22. Sonti SS, Barbero EJ (1996) Material Characterization of Pultruded Laminates and Shapes. J Reinf Plast Comp 15: 701-717.

23. Hag N and Harrison P (1996) Corrosion Preventing and Control, 43: 162.

24. Singh BP, Jain RC and Bharadwaj IS (1994) Synthesis, Characterization and Properties of Vinyl Ester Matrix Resins. J Polym Sci 2: 941.

25. Brown JR and Mathys Z (1997) Mechanical Properties of Fire-damaged Glassreinforced Phenolic Composites. Composites 28: 675.

26. Bahadur S, Tabor D (1985) Role of Fillers in the Friction and Wear Behavior of High-Density Polyethylene. Polymer Wear and Its Control 17: 253-268.
27. Tanaka K (1982) Transfer of semicrystalline polymers sliding against smooth steel surface. Wear 75: 183-199.

28. Gahr KHZ (1987) Microstructure and Wear of Materials. Elsevier, Netherlands

29. Bahadur S (1978) Wear research and development. J Lub Tech 100: 449-454

30. Bolvari AE, Glenn SB (1996) Abrasive wear of polymer composites. Eng Plast 9: 205-215.

31. Kishore, Sampathkumaran P, Seetharamu S, Murali A, Kumar RK (2001) On the SEM features of glass-epoxy composite system subjected to dry sliding wear. Wear 247: 208-213.

32. Bolvari A, Glenn S, Janssen R, Ellis C (1997) Wear and friction of aramid fibe and polytetrafluoroethylene filled composites. Wear 204: 697-702.

33. Evans DC (1978) Polymer fluid interaction in relation to wear. In proceeding of the third Leeds-Lyon Symposium on Tribology, the wear of Non Metallic Materials Mechanical Engineering Publications Ltd. 47-55.

34. Tanaka K (1980) Friction and Wear of Semicrystalline Polymers Sliding Against Steel Under Water Lubrication. J Lub Tech 102: 526-533.

35. Unal H, Mimaroglu A (2006) Friction and wear characteristics of PEEK and its Composite Under Water Lubrication. J Reinf Plast Comp 16: 1659-1667.

36. El-Tayeb NS, Gadelrab RM (1996) Friction and wear properties of E-glass fibe reinforced epoxy composites under different sliding contact conditions. Wear 192: 112-117.

37. Sumer M, Unal H, Mimaroglu A (2008) Evaluation of tribological behavior of PEEK and glass fiber reinforced PEEK composite under dry sliding and water lubricated conditions. Wear 265: 1061-1065.

38. Lancaster JK (1972) Lubrication of carbon fiber-reinforced polymers part-1: water and aqueous solutions. Wear 20: 315-333. 